[Agr. Biol. Chem., Vol. 28, No. 10, p. 694 699, 1964]

\title{
Production of Nucleic Acid Related Substances by Fermentative Processes
}

\author{
Part VI. Accumulation of 5'-Xanthylic Acid by Guanine-Requiring \\ Mutants of Micrococcus glutamicus \\ II. Studies on Cultural Conditions
}

By Masanaru Mrsawa, Takashi Nara and Shukuo Krnoshrta

Tokyo Research Laboratory, Kyowa Hakko Kogyo Co., Ltd.

Received March 21, 1964

\begin{abstract}
A guanineless mutant of Micrococcus glutamicus, KY9978 strain, which was derived from a guanine-adenine doubleless mutant, KY9938 strain, was able to grow on guanine more abundantly than the corresponding nucleoside and nucleotide, but unable to grow on 2,6-diaminopurine. A fermentation medium most suitable for XMP production by KY9978 strain was decided by varying the concentrations and kinds of ingredients in the medium. Of particular importance in media is the concentration of guanine, the excessive addition of which decreased XMP yields remarkably. This might suggest negative feed back mechanisms involved in GMP biosynthesis by this strain. Typical chemical changes in XMP fermentation showed that the maximal amount of the product was approximately $2.75 \mathrm{mg}$ per $\mathrm{ml}$ of medium.
\end{abstract}

\section{INTRODUCTION}

It was previously reported that guanineless or guanine-adenine doubleless mutants of Micrococcus glutamicus accumulated a large amount of 5'xanthylic acid (abbreviated as XMP) in the culture fluid."

In this report, the results on growth response of the organisms and on experiments to develop a complex medium suitable for XMP production by the organisms are described.

\section{EXPERIMENTAL}

\section{Materials and Methods}

M. glutamicus KY9978 (a guanine-requiring mutant) was used exclusively in these experiments.

Materials and methods are the same as in the previous repor ${ }^{11}$ with the exception of the tests for growth response. Procedures for growth response tests are as follows: 1 drop of cell suspension which was prepared by addition

1) M. Misawa, T. Nara, K. Udagawa, S. Abe and S. Kinoshita, This Journal, 28, 688 (1964). of $10 \mathrm{ml}$ of sterilized water to an agar slant culture of KY9978 strain, was inoculated to $10 \mathrm{ml}$ of the growth medium in a test tube. It was incubated at $30^{\circ} \mathrm{C}$ with shaking. After 2 days, the cell density was assayed by the same method as described previously." ${ }^{1}$ The chemically defined medium comprising casamino acids (vitamin free) as amino acid source, necessary for growth of the organism, ${ }^{2)}$ was used for the test. The composition of the medium is shown in Fig. 1.

\section{RESULTS}

\section{Growth Response of KY 9978 Strain.}

The growth response of KY9978 strain th guanine, its derivatives and 2,6-diaminopurin was first tested. The results are given in Fig. 1

It was observed that the most abundan growth of the mutant was obtained by guanin supplement, whereas its growth was very poo on a medium to which guanosine or $5^{\prime}$-guanyli acid was added. Addition of approximatel

\footnotetext{
2) K. Nakayama, Z. Sato and S. Kinoshita, Oral presentation * Meeting of Agr, Chem. Society, Tokyo. Nov, 1963.
} 


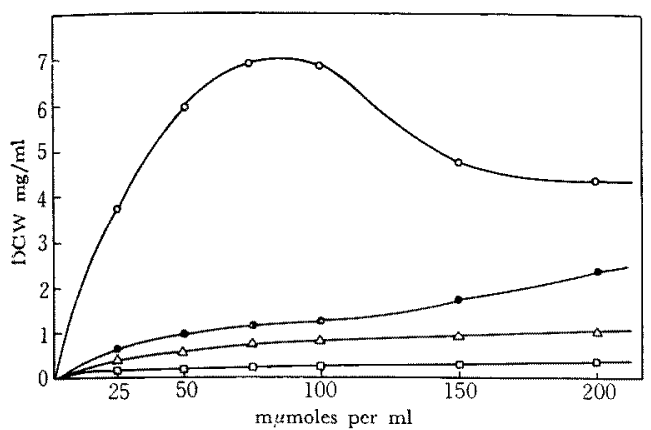

F1G. 1. Growth Responses of KY9978 Strain to Guanine Derivatives.

Medium: Glucose $2.0 \%,\left(\mathrm{NH}_{4}\right)_{2} \mathrm{SO}_{4} 0.4 \%$, casamino acids $1.0 \%$ $\mathrm{K}_{2} \mathrm{HPO}_{4} 0.1 \%$, urea $0.1 \%$, vitamin mixture $1 \mathrm{ml} / 100 \mathrm{ml}$ and $\mathrm{MgSO}_{4} \cdot 7 \mathrm{aq} 0.03 \%$, FeSO, 7 aq $0.01 \%, \mathrm{CaCl}_{2} \cdot 2 \mathrm{aq}$ $0.01 \%$.

26 DAP : 2.6 Diaminopurine, DGW.: Dried Cell Weight.

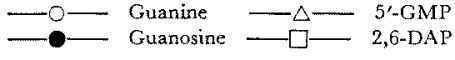

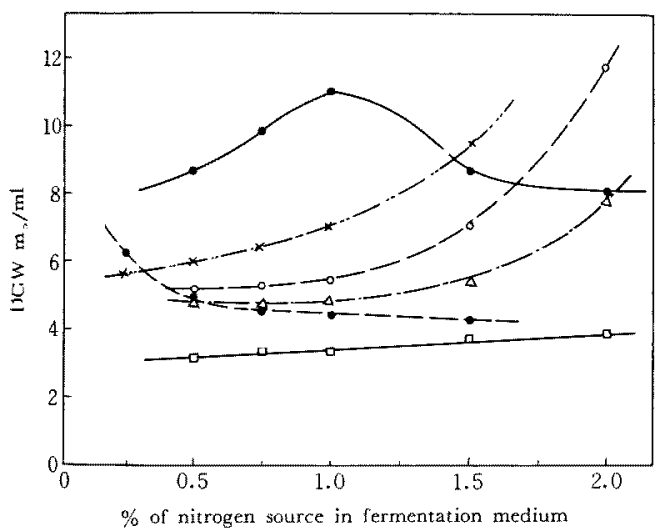

FIG. 2. Effect on Growth of KY9938 Strain of Nitrogen Sources in Fermentation Media.

Basal medium: glucose $10.0 \%$, yeast extract $1.0 \%, \mathrm{MgSO}_{4} \cdot 7 \mathrm{Taq}$ $0.1 \%, \mathrm{CaCO}_{2} 2.0 \%, \mathrm{~K}_{2} \mathrm{HPO}_{4} 0.2 \%$ and $\mathrm{KH}_{2} \mathrm{PO}_{4} 0.2 \%$.

Nitrogen sources were added to this basal medium, as indicated

in Figure.

* When urea was used as a nitrogen source. $\mathrm{CaCO}_{3}$ was not present in the medium.

After 6-day incubation

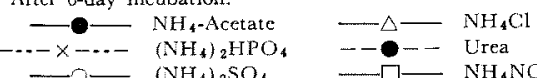

$80 \mathrm{~m} \mu$ moles of guanine to the medium gave the maximal growth. On the other hand, adenine, hypoxanthine, xanthine, the corresponding ribosides and ribotides failed to support the growth of the organism.

3) B. Magasanik and M.S. Brooke, J. Biol. Chem. 206, 83 (1954), 4) N. Fries, ibid., 200, 325 (1953).

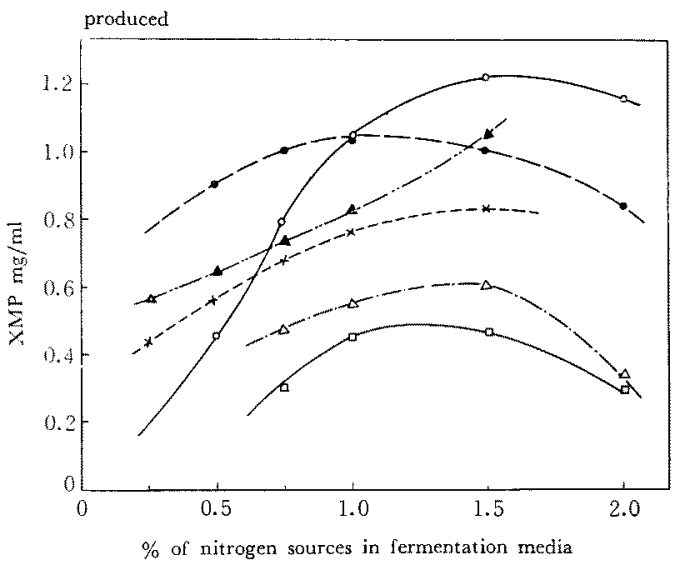

FIG. 3. Effect on XMP Accumulation by KY 9938 Strain of Nitragen Sources in Fermentation Media.

Fermentation medium (Basal): Glucose $10.0 \%$, yease extract $1.0 \%$, $\mathrm{KH}_{2} \mathrm{PO}_{4} 0.2 \%, \mathrm{~K}_{2} \mathrm{HPO}_{4} 0.2 \%, \mathrm{MgSO}_{4} \cdot 7 \mathrm{aq} 0.1 \%$ and $\mathrm{CaCO}$ $2 \%$.

Nitrogen sources were added to this basal medium, as indicated in Figure.

* When urea was used as a nitrogen source, $\mathrm{CaCO} \&$ was not contained in the medium.

$$
\begin{aligned}
& \left.-\mathrm{O}-\mathrm{NH}_{4}\right)_{2} \mathrm{SO}_{4} \quad---\times--- \text { Urea } \\
& \left.\square-\mathrm{NH}_{4} \mathrm{NO}_{3} \quad \cdots-.-\mathrm{NH}_{4}\right)_{2} \mathrm{HPO}_{4}
\end{aligned}
$$

Moreover, it could not grow on 2,6-diaminopurine, in contrast with previous findings that the guanine-auxotroph of Aerobacter aerogenes, ${ }^{3)}$ or Ophiostoma multianulatum ${ }^{4}$ is able to grow on 2,6-diaminopurine instead of guanine.

\section{Inorganic Nitrogen Sources.}

In attempt to find out media giving better yields of XMP, various inorganic nitrogenous compounds were used as nitrogen sources in the XMP fermentation.

As shown in Fig. 2, all of the nitrogen compounds tested were able to support the growth of the cells and especially ammonium sulfate gave the most abundant growth. The amounts of XMP accumulated on various concentrations of these compounds are shown in Fig. 3. From these results, ammonium sulfate was found to be the best nitrogen source not only for the accumulation of XMP but also for the growth.

\section{Carbon Sources.}

The organism could utilize glucose, sucrose, fructose maltose and mannose as carbon sources. 


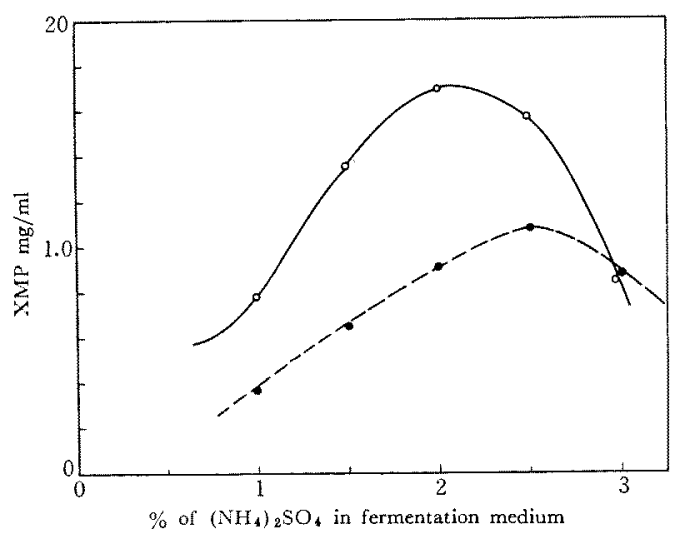

FIG. 4. Effects of Sterilization Method of Glucose on XMP Fermentation.

Fermentation medium : Glucose $10.0 \%$, Yeast extract $1.0 \%, \mathrm{KH}_{2} \mathrm{PO}_{4}$, $0.2 \%, \mathrm{~K}_{2} \mathrm{HPO}_{4} 0.2 \%, \mathrm{MgSO}_{4} \cdot 7 \mathrm{aq} .0 .1 \%$ and $\mathrm{CaCO}_{8} 2.0 \%$. Sirnultaneously: Glucose was sterilized simultaneously with the other components in the medium.

Separately: Glucose was sterilized separately from the other conponents in the medium.

Assayed for 6-day culture broth.

$$
\begin{array}{ll}
-0-\text { Separately. } \\
---\infty & \text { Simultaneously. }
\end{array}
$$

Although it grew more sufficiently on maltose than on the other sugars, the strain accumulated the highest level of XMP on glucose. It was further observed that the simultaneous sterilization of glucose with the other component in the medium reduced the yield of the product (Fig. 4). Therefore, glucose autoclaved separately was added to the media just prior to inoculation.

\section{Inorganic Phosphate and Magnesium.}

The levels of both inorganic phosphate and magnesium sulfate in the fermentation medium affected both the growth of the cells and XMP yields. (Table I). The high levels of monobasic, dibasic potassium phosphates and magnesium sulfate in the medium inhibited the growth of the cells. The most suitable levels of these salts for XMP production were decided to be approximately $0.2 \%$ of $\mathrm{KH}_{2} \mathrm{PO}_{4}, 0.2 \%$ of $\mathrm{K}_{2} \mathrm{HPO}_{4}$ and $0.4 \%$ of $\mathrm{MgSO}_{4} \cdot 7 \mathrm{H}_{2} \mathrm{O}$.

\section{Natural Nitrogen Sources.}

The supplement to fermentation media of natural nitrogen sources such as peptone, casamino acids and NZ-amine stimulated XMP production by KY9938 culture. The results
Table I. EFfect on XMP Fermentation of Inorganic Phosphate and Magnesium IN FERmentation Medium

\begin{tabular}{|c|c|c|c|c|}
\hline \multirow{2}{*}{$\begin{array}{c}\mathrm{KH}_{2} \mathrm{PO}_{4} \\
\mathrm{~K}_{2} \mathrm{HPO}_{4} \\
\text { (each) }\end{array}$} & \multirow{2}{*}{$\begin{array}{c}\mathrm{MgSO}_{4} \cdot 7 \mathrm{H}_{2} \mathrm{O} \\
\%\end{array}$} & \multicolumn{3}{|c|}{ 4-day incubation } \\
\hline & & $\mathrm{pH}$ & $\begin{array}{c}\mathrm{DCW} \\
\mathrm{mg} / \mathrm{ml}\end{array}$ & $\begin{array}{c}\mathrm{XMP} \\
\mathrm{mg} / \mathrm{ml}\end{array}$ \\
\hline \multirow{5}{*}{$0.1 \%$} & 0.05 & 5.1 & 18.1 & 0.70 \\
\hline & 0.1 & 5.0 & 18.0 & 1.17 \\
\hline & 0.2 & 4.9 & 16.2 & 1.26 \\
\hline & 0.4 & 5.0 & 17.6 & 1.29 \\
\hline & 0.6 & 5.0 & 17.6 & 0.93 \\
\hline \multirow{5}{*}{$0.2 \%$} & 0.05 & 4.8 & 15.1 & 1.41 \\
\hline & 0.1 & 5.0 & 18.4 & 1.28 \\
\hline & 0.2 & 4.9 & 11.0 & 1.40 \\
\hline & 0.4 & 4.8 & 11.2 & 1.71 \\
\hline & 0.6 & 4.8 & 11.8 & 1.29 \\
\hline \multirow{5}{*}{$0.4 \%$} & 0.05 & 4.6 & 15.4 & 1.39 \\
\hline & 0.1 & 4.6 & 13.9 & 1.32 \\
\hline & 0.2 & 5.0 & 13.8 & 0.75 \\
\hline & 0.4 & 4.8 & 9.4 & 0.66 \\
\hline & 0.6 & 4.7 & 10.1 & 0.62 \\
\hline \multirow{5}{*}{$0.6 \%$} & 0.05 & 4.8 & 8.3 & 0.78 \\
\hline & 0.1 & 4.7 & 7.8 & 0.80 \\
\hline & 0.2 & 4.8 & 8.1 & 0.73 \\
\hline & 0.4 & 4.8 & 8.2 & 0.74 \\
\hline & 0.6 & 4.9 & 7.0 & 0.59 \\
\hline
\end{tabular}

Basal medium: Glucose $10.0 \%,\left(\mathrm{NH}_{4}\right)_{2} \mathrm{SO}_{4} 2.0 \%$ veast extract $1.0 \%$, and $\mathrm{CaCO}_{3} 2 \%$.

$\mathrm{KH}_{2} \mathrm{PO}_{4}, \mathrm{~K}_{2} \mathrm{HPO}_{4}$ and $\mathrm{MgSO}_{4} \cdot 7 \mathrm{H}_{2} \mathrm{O}$ were added to this basal medium, as indicated in Table.

are shown in Fig. 5. Addition of NZ-amine or peptone (up to as much as $1.5 \%$ ) resulted in more accumulation of XMP, whereas addition of casamino acids more than $0.5 \%$ decreased the yields.

Trace Elements.

Effects of trace elements on growth are shown in Fig. 6. $\mathrm{Zn}^{++}, \mathrm{Co}^{++}, \mathrm{Cu}^{++}$and $\mathrm{Ni}^{++}$inhibited remarkably growth of KY9938 strain at the level of $0.1 \%$, while no inhibitory effect on growth was noted in media containing $\mathrm{Fe}^{++}, \mathrm{Mn}^{++}$ and $\mathrm{Ba}^{++}$at the same level. Obviously, the growth inhibition by the higher levels of trace elements resulted in lowering of XMP titres.

\section{Effect of Guanine on XMP Accumulation.}

It is wellknown that in various fermentations with biochemical auxotrophs, quantities of a 


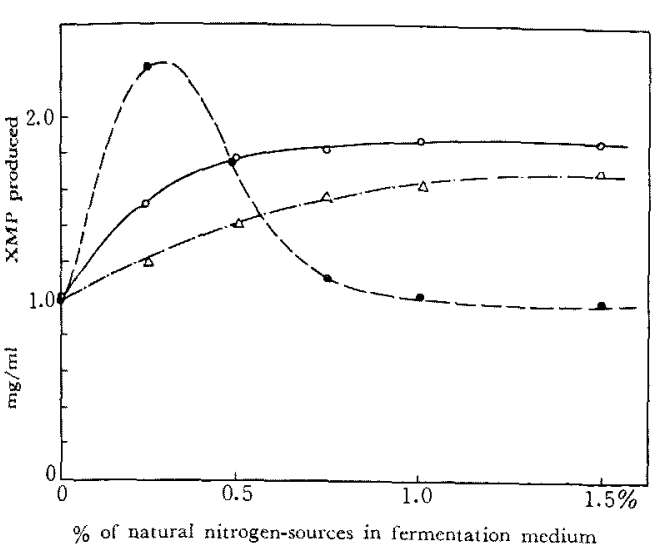

FIG. 5. Effect on XMP Production of Natural Nitrogen Sources.

Fermentation medium (Basal): Glucose $10.0 \%$, yeast extract $1.0 \%$, $\mathrm{KH}_{2} \mathrm{PO}, 0.2 \%, \mathrm{~K}_{2} \mathrm{HPO}_{4} \quad 0.2 \%, \mathrm{MgSO}_{4} \cdot 7 \mathrm{aq} .0 .4 \%$ and $\mathrm{CaCO}_{8} 2 \%$.

Natural nitrogen sources were added to this basal medium, as indicated in Figure. Assayed for 6-day culture broth.

$$
\begin{aligned}
& \text { - O- NZ-amine } \\
& \text { - - Peptone } \\
& \text {---.- Casamino acids }
\end{aligned}
$$

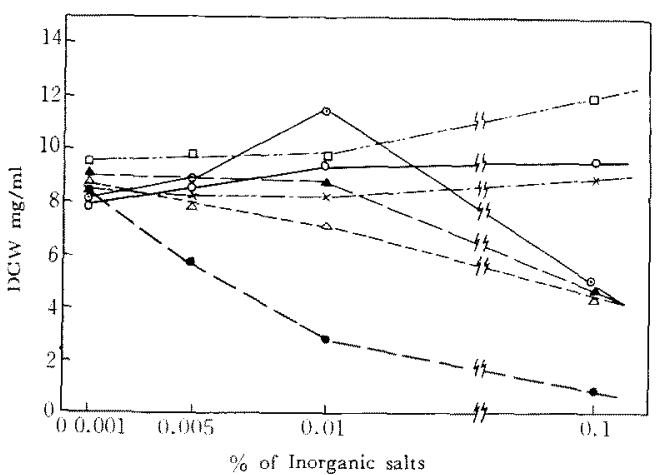

FIG. 6. Effect of Trace Elements on Growth of KY 9938 Strain.

Fermentation medium (Basal): Glucose $10.0 \%, \mathrm{KH}_{2} \mathrm{PO}$, $0.2 \%$, $\mathrm{K}_{2} \mathrm{HPO}_{4} 0.2 \%, \mathrm{MgSO} \cdot 7 \mathrm{H}_{2} \mathrm{O} 0.4 \%, \mathrm{CaCO}_{3} 2.0 \%$, Yeast extract $1.0 \%,\left(\mathrm{NH}_{4}\right)_{2} \mathrm{SO}, 2.0 \%$ and $\mathrm{NZ}$-amine $0.75 \%$.

Trace elements were added to this medium, as indicated in Figure. Assayed for 6-day culture broth.

$$
\begin{aligned}
& -\cdots-\square---\mathrm{BaCl}_{2} \cdot 2 \mathrm{aq} . \quad--\mathbf{A}--\mathrm{NiCl}_{2} 6 \mathrm{aq} \text {. }
\end{aligned}
$$

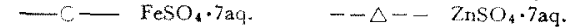

$$
\begin{aligned}
& -\cdot x-+\mathrm{MnSO}_{4} 4 \mathrm{aq} \text {. } \quad--\mathrm{O}-\mathrm{CoCl}_{2} \text { faq. } \\
& -3-\text { CusO.5aq. }
\end{aligned}
$$

required nutrient added to media exert a marked effect on the amounts of accumulated product. Effects of guanine required by Krg938 strain were examined on XMP fermentation. The results are summarized in Fig. 7 and Fig. 8.

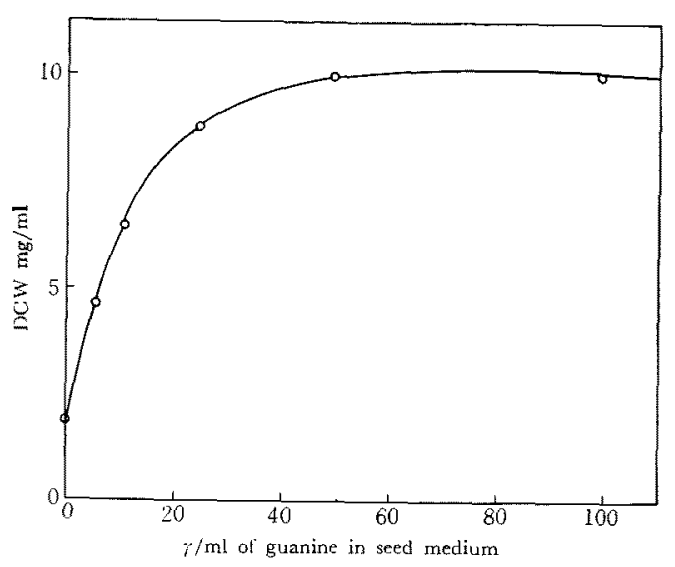

Fig. 7. Effect of Guanine in Growth of KY 9978 Strain in Seed Medium.

Seed medium: Glucose $2.0 \%$, yeast extract $1.0 \%$, peptone $1.0 \%$, and NaCil $0.25 \%$.

Guanine was added to this medium, as indicated in Figure. Assayed for 2thour culture.

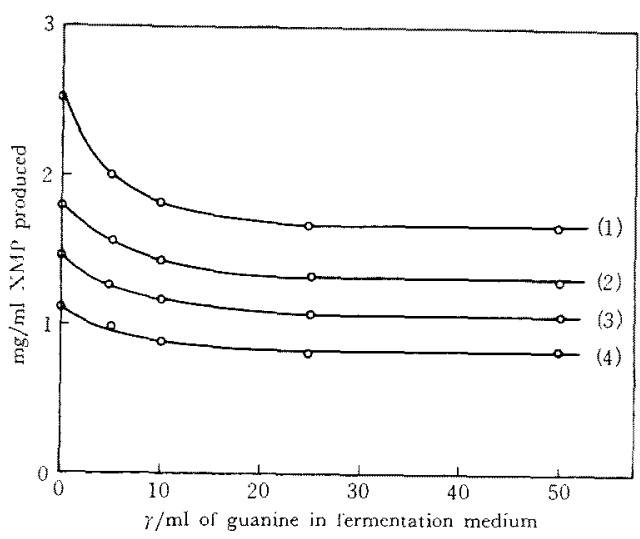

FIG. 8. Effect of Guanine in Media on XMP Accumulation by KY9978 Strain.

Seed mediurn: Glucose $2.0 \%$, Yeast extract $1.0 \%$, peptone $1.0 \%$ and $\mathrm{NaCl} 0.25 \%$

Fermentation medium: Glucose $10.0 \%, \mathrm{KH}_{2} \mathrm{PO}_{4} 0.2 \%, \mathrm{MgSO}_{4}$ $7 \mathrm{H}_{2} \mathrm{O} 0.4 \%$, yeast extract $1.0 \%,\left(\mathrm{NH}_{4}\right)_{2} \mathrm{SO}_{4} 2.0 \%$ and $\mathrm{CaCO}_{3}$

$2.0 \%$. Guanine was added to this medium, as indicated in Figure.

Assayed for 6-day culture broth.

Guanine in secd medium

$$
\begin{aligned}
& \text { (1) } 0 \% / \mathrm{ml} \\
& \text { (2) } 10 \% / \mathrm{ml} \\
& \text { (3) } 50 \% / \mathrm{ml} \\
& \text { (4) } 100 \% / \mathrm{ml}
\end{aligned}
$$

Growth on the seed medium was more stimulated by further increment of guanine concentration up to about $50 \mathrm{r}$ per $\mathrm{ml}$ of medium (Fig. 
7). The seed cultures grown on media containing various concentration of guanine was inoculated to fermentation media containing various levels of guanine up to $50 \mathrm{r}$ per $\mathrm{ml}$.

Excessive addition of guanine to fermentation media suppressed the accumulation of XMP and the presence of guanine in seed media also reduced the yield of the product appreciably.

The growth stimulatory effect of guanine in fermentation media was not clear at the final stage of the fermentation, since the media comprised $1.0 \%$ of yeast extract which contained guanine compounds. At an early stage of the fermentation, however, guanine addition evidently stimulated the growth.

\section{The Chemical Changes in XMP Fermentation.}

As stated above, the medium most suitable for accumulation of XMP was established with
KY9938 strain. The developed medium consists of $10 \%$ of glucose, $2.0 \%$ of $\left(\mathrm{NH}_{4}\right)_{2} \mathrm{SO}_{4}, 0.2 \%$ of $\mathrm{KH}_{2} \mathrm{PO}_{4}, 0.4 \%$ of $\mathrm{MgSO}_{4} \cdot 7 \mathrm{H}_{2} \mathrm{O}, 1.0 \%$ of yeast extract, $0.5 \%$ of peptone and $2.0 \%$ of $\mathrm{CaCO}_{3}$. Typical chemical changes in XMP fermentation on the medium are given in Fig. 9. The time course shows that XMP began to accumulate after 1-day, and reached its maximal yields around 5-days. Glucose was consumed completely after 5-days and the cells were increased gradually. A small amount of xanthine was accumulated at the earlier stage, but decreased at the later stage. Since $\mathrm{pH}$ of the medium was not controlled, it was adjusted to 4.8 at 2 days' incubation, but increased gradually after 5 days. The maximal amount of XMP accumulated was $2.75 \mathrm{mg}$ per $\mathrm{ml}$ of medium.

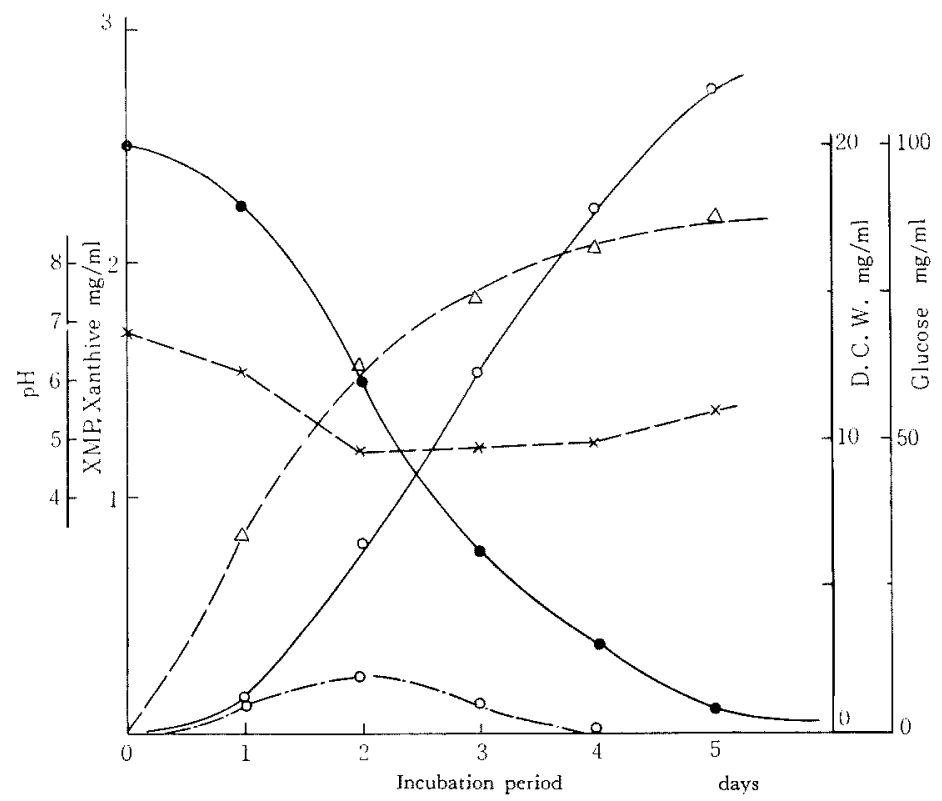

FIG. 9. A Typical Chamical Change in XMP Fermentation.

Seed medium: Glucose $2.0 \%$, yeast extract $1.0 \%$, peptone $1.0 \%$ and $\mathrm{NaCl} 0.25 \%$

Fermentation medium: Glucose $10.0 \%,\left(\mathrm{NH}_{4}\right)_{2} \mathrm{SO}_{4} 2.0 \%$, yeast extract $1.0 \%$, peptone $0.5 \%, \mathrm{KH}_{2} \mathrm{PO} \mathrm{O}_{4} 0.2 \%, \mathrm{~K}_{2} \mathrm{HPO}_{4} 0.2 \%$, $\mathrm{MgSO}_{4} \cdot 7 \mathrm{H}_{2} \mathrm{O} 0.4 \%$ and $\mathrm{CaCO}_{3} 2.0 \%$.

$\longrightarrow$ XMP, $-\Delta--$ D.C.W., $--x-\cdots \mathrm{pH}$

- Glucose, -..-O-... Xanthine

5) K. Ogata, Amino Acids and Nucleit Acid, 8, 1 (1963).

6) S. Kinoshita, J. Ferm. Assoc. Japan, 22, 101 (1964).

7) K. Nakayama, T. Suzuki, Z. Sato and S. Kinoshita, Oral Presentation at Symposium on Amino Acid and Nucleic Acid Fermentation, Kyoto, Nov, 1963.

\section{DISCUSSION}

To the end of producing compounds related to nucleic acid, such as $5^{\prime}$-inosinic, guanylic and 
xanthylic acids, many investigations ${ }^{5,6)}$ have recently been focused on microbial accumulation of these compounds, which have been used for seasonings.

However, the production of XMP by fermentation processes has not yet been reported. Nakayama et al. ${ }^{3}$ in our laboratory have recently reported the accumulation of 5 -inosinic acid by adenine-requiring mutants of Micrococcus glutamicus.

Under such circumstances, we found that guanine or guanine-adenine requiring mutants of $M$. glutamicus accumulated a large amount of $5^{\prime}$-XMP. Such a marked excretion of XMP might be ascribed to a genetic blocking of XMP aminase, responsible for the conversion of XMP to GMP, as already reported by Magasanik ${ }^{3)}$

The facts that the guanineless mutant of Aerobacter aerogenes ${ }^{3>}$ accumulates xanthosine, whereas those of $M$. glutamicus produce XMP are speculated to reflect significant differences of phosphatase activities between both cultures as reported previously. ${ }^{82}$

One of the guanine-requiring mutants of $M$. glutamicus, KY9978 strain, was selected as the best strain for XMP production. Guanine supported the most abundant growth of the strain as compared with the corresponding nucleotide and nucleoside. It is therefore suggested that guanine may be more permeable into the cells than other derivatives or that the activities of

8) M. Misawa, T. Nara and K. Nakayama, J. Agr. Chem, Soc. (Japan), 38, $167(1064)$. cleavable enzymes of nucleotide or nucleoside, such as phosphatase, nucleosidase and so on are lower in this culture.

It has been demonstrated that the guanineless mutants of Aerobacter aerogenes ${ }^{3)}$, Salmonella typhimurium ${ }^{93}$ or Ophiostoma multianulatum ${ }^{4}$ are able to grow on 2,6-diaminopurine, instead of guanine, whereas the KY 9978 strain cannot grow on the compound. This finding indicates that 2,6-diaminopurine may not be converted to guanine in our strain.

Of particular importance in this fermentation is a fact that an excess addition of guanine to media inhibited the accumulation of XMP. This phenomenon could be accounted for by "negative feed back mechanisms" involved in the biosynthesis of purine nucleotide. In particular, it is of extreme interest regarding XMP biosynthesis that inosinic acid dehydrogenase in Enterobacteriaceae $^{10}$ ) involved in the conversion of inosinic acid to XMP is repressed by guanine.

At any rate, possible operation of such control mechanisms in KY 9978 culture is only speculative.

Further enzymatic approaches must be awaited to dissolve the reason why guanine suppresses the XMP accumulation by $M$. glutamicus $\mathrm{KY}$ 9978 strain. Experiments along such lines are now in progress.

\footnotetext{
9 G.P. Kalle and J. Gots, J. Bast 81, 331 (1961).

10) A.P. Levin and B. Magasanik, J. Biol. Chem. 236, 184 (1961).
} 